\title{
Impact of removable dentures on oral health-related quality of life among elderly adults in Taiwan
}

Yea-Yin Yen ${ }^{1}$, Huey-Er Lee ${ }^{2,3}$, Yi-Min Wu ${ }^{1,4}$, Shou-Jen Lan ${ }^{5}$, Wen-Chen Wang ${ }^{2,6,7}$, Je-Kang Du²,3, Shun-Te Huang ${ }^{1,8}$ and Kun-Jung Hsu ${ }^{9,10^{*}}$

\begin{abstract}
Background: Although the use of removable dentures can improve oral function and esthetics for elderly people, compared to those who do not wear removable dentures, those wearing removable dentures could have worse oral health related-quality of life $(\mathrm{OHRQOL})$. Additional information is required to assess which factors related to denture wearing influence the OHRQoL of elderly individuals. The purpose of this study is to evaluate the association between denture wearing and OHRQoL in a sample of elderly individuals in Taiwan.

Methods: The study population included 277 elderly people wearing removable dentures (mean age $=76.0$ years). Using face-to-face interviews, we collected data on the participants' socio-demographic characteristics, dental care service usage (regular dental checkups, treatment during toothache, dental visits in the last year), and factors related to denture wearing (perceived oral pain, perceived loose denture, perceived oral ulcer, perceived halitosis, perceived dry mouth, and perceived total denture satisfaction scores). OHRQoL was measured using the Taiwanese version of the Geriatric Oral Health Assessment Index (GOHAl-T). The location and number of remaining natural teeth and the type of denture were also recorded. Hierarchical multiple regression analysis was performed using GOHAI-T scores as the dependent variable.
\end{abstract}

Results: All the predictors together accounted for $50 \%$ of the variance in GOHAl-T scores. Further, education level, number of natural teeth, denture status, perceived loose denture, perceived oral ulcer, and perceived total denture satisfaction scores had statistically significant influences on OHRQoL. When compared with other variables, factors related to denture wearing, especially perceived total denture satisfaction scores, had the greatest impact on GOHAl-T scores.

Conclusions: Of the factors analyzed in this study, denture satisfaction was the strongest predictor of OHRQoL. This suggests that denture satisfaction is useful for assessing the effect of denture treatment on the OHRQoL of elderly individuals wearing removable dentures.

Keywords: Elderly, Removable dental prostheses, Oral health-related quality of life, Geriatric oral health assessment index, Denture satisfaction, Dental care service

\footnotetext{
* Correspondence: taihen.n4545@msa.hinet.net

${ }^{9}$ Division of Family Dentistry, Department of Dentistry, Kaohsiung Medical University

Hospital, Kaohsiung, Taiwan

${ }^{10}$ Department of Dentistry, Kaohsiung Municipal Ci-Jin Hospital, Kaohsiung,

Taiwan

Full list of author information is available at the end of the article
}

\section{Biomed Central}

(c) 2015 Yen et al.; licensee BioMed Central. This is an Open Access article distributed under the terms of the Creative Commons Attribution License (http://creativecommons.org/licenses/by/4.0), which permits unrestricted use, distribution, and reproduction in any medium, provided the original work is properly credited. The Creative Commons Public Domain Dedication waiver (http://creativecommons.org/publicdomain/zero/1.0/) applies to the data made available in this article, unless otherwise stated. 


\section{Background}

Because of the low fertility rate in Taiwan [1], the elderly population is rapidly increasing. By the end of 2026, people aged 65 years or over are expected to account for $20.1 \%$ of the total population of Taiwan [2], and, as such, there is a growing interest in helping the elderly to live a complete and healthy life, physically, mentally, and socially [3]. Oral health is an important part of well-being, and oral health-related quality of life (OHRQoL) should be emphasized when providing dental care to elderly people. One of the most commonly used measures of OHRQoL is the Geriatric Oral Health Assessment Index (GOHAI), which was developed specifically for use with older adults [4].

Many previous studies have shown that implant-supported dentures can substantially improve the wearer's quality of life [5]; however, the higher cost of treatment with dental implants means that removable dentures continue to be widely used to replace missing teeth [6], especially in the elderly [7]. Unfortunately, individuals wearing a removable prosthesis can experience significant problems with regard to the social and emotional aspects of life, as compared to individuals with natural teeth [8]. It maybe difficult for some individuals to adapt to dentures, as wearing a removable prosthesis demands emotional and functional adjustments [9]. As such, elderly individuals wearing removable dentures may experience more OHRQoL impairments than do those who do not wear removable dentures.

In elderly people, OHRQoL is known to be associated with socioeconomic status [10-13], regular dental visits [14], subjective masticatory ability [15], and the number of remaining natural teeth $[12,14,16-18]$. Factors related to denture wearing that specifically affect the OHRQoL of elderly people wearing removable dentures include denture status [18-21], denture satisfaction [10,19], perceived loose denture [11,22,23], presence of oral pain [24], presence of oral ulcer [13], perceived halitosis [25] and perceived dry mouth [17]. Kuo et al. [7] found that increased denture satisfaction was significantly related to an improvement in elderly patients' OHRQoL. In addition, Komagamine et al. [22] showed a positive relationship between retention of the lower denture and OHRQoL, using the Oral Health Impact Profile (OHIP), in edentulous patients. Moreover, Ekanayake et al. [16] reported a significant association between halitosis and higher OHIP scores, indicating that people with halitosis had a worse OHRQoL than those who did not have halitosis.

In addition, a previous study indicated that elderly patients' denture satisfaction is associated with healthrelated quality of life (HRQoL) [10]. However, Inoue et al. [26] showed that HRQoL in patients with removable dentures was mediated by OHRQoL. Moreover, Lee et al. [27] observed that perceived oral health status, measured by the OHIP, had a greater impact on HRQoL than did the clinical factors, as measured by the 36-Item Short Form (SF-36) Health Survey. Therefore, it is important to assess the predictors of OHRQoL to improve HRQoL.

A previous study showed that although denture wearing could improve oral function and esthetics related to quality of life, people wearing removable dentures had a significantly higher median OHIP score than did those who do not wear removable dentures, indicating a poorer OHRQoL in the former group [16]. Hence, additional information is required to determine which factors related to denture wearing influence the OHRQoL of elderly subjects. Improved understanding of the factors correlated with a better OHRQoL would help in clinical decision making to provide dental treatment appropriate for patients' specific needs and concerns. Although the relationship between variables related to denture wearing and OHRQoL has been investigated in previous studies $[19,22]$, it is unclear which variable is the strongest predictor of OHRQoL. Therefore, in the current study, we aimed to address this gap in the literature. The research hypothesis was that denture satisfaction would be the strongest predictor of OHRQoL among the variables mentioned above that relate to wearing of removable dentures.

\section{Methods}

\section{Participants}

This was a cross-sectional study carried out from September 2009 to January 2010. A convenience sample of elderly subjects aged 65 years or over who wore removable dentures was recruited from the Kaohsiung City Government Senior Citizens' Service. Subjects were excluded from the study for the following reasons: 1 . did not complete the questionnaire; 2 . did not eat the foods listed in the questionnaire due to religious beliefs, vegetarianism, or other personal reasons; 3 . had three or more incorrect answers on the Short Portable Mental Status Questionnaire (SPMSQ), indicating mild to severe intellectual impairment [28].Nine subjects were excluded from the study, 5 of them were vegetarian, 3 did not complete their questionnaire and additional 1 subject was mild intellectual impairment.

In the present study, the SPMSQ was used to evaluate the participants' ability to understand the questionnaire. The cognitive status of elderly individuals was defined as the number of wrong answers in the 10-question SPMSQ, whereby two or fewer incorrect answers indicate an intact cognitive status, three or four incorrect answers indicate mild intellectual impairment, and five or more incorrect answers indicate moderate to severe intellectual impairment.

Written informed consent was obtained from all subjects prior to data collection. Ethical approval was obtained from the Institutional Review Board at Chung-Ho 
Memorial Hospital, Kaohsiung Medical University (KMUHIRB-980273).

\section{Questionnaire}

Information obtained by questionnaires included sociodemographic characteristics (age, gender, education level, living alone or with others, and the ability to afford living expenses), factors related to denture wearing (presence of oral pain, perceived loose denture, presence of oral ulcer, perceived halitosis, perceived dry mouth, and satisfaction with removable dentures), dental health service usage (regular dental checkups, treatment during toothache, dental visits in the last year), and OHRQoL, (as measured using the GOHAI).

OHRQoL was measured using the GOHAI, which was originally developed for use in older adult populations [4]. The GOHAI instrument provides a score based on the answers to 12 questions associated with the following three domains of OHRQoL: physical function (PF), including eating, speech, and swallowing; psychosocial function (PSF), including worry or concern about oral health, dissatisfaction with appearance, self-consciousness about oral health, and avoidance of social contact because of oral problems; and pain or discomfort (PD), including the use of medication to relieve pain or discomfort in the mouth. Score ranges for the dimensions of physical function, psychosocial function, and pain or discomfort are4-20, 5-25, and 3-15, respectively.

The original English Version of the GOHAI was translated into Chinese for use with Taiwanese people (GOHAI-T; see Table 1). A panel of professional experts carried out and verified the translation and cross-cultural adaptation of the original English version. Responses to GOHAI-T items were assessed using a 5-point Likert scale, ranging from $1=$ always to $5=$ never. Total scores on the GOHAI-T were a summation of all individual scores obtained from the 12 items, with a higher score indicating a lower impact on OHRQoL (range of sum score $=12-60$ ). Denture satisfaction was evaluated by a denture-satisfaction assessment (DSA). In previous studies in which the DSA was utilized, six questions were used to evaluate the level of subjects' satisfaction with their removable dentures [29-31]. The questions were related to tasting, retention (including upper and lower dentures), esthetics, comfort (including upper and lower dentures), appearance, ability to speak, and mastication ability. Subjects' satisfaction was recorded using a 5 -point Likert scale, wherein the scores ranged from 1 (very unsatisfied) to 5 (very satisfied). The scores for questions concerning retention and comfort of the dentures were calculated as average scores of the upper and lower dentures. Subjects' responses to the six questions are summed to obtain a total denture satisfaction score. The sum score can range from 6 to 30, with a higher score indicating more satisfaction with the dentures.

\section{Dental examination}

The dental examinations were carried out by one of the authors, a family dentistry specialist with 15 years of clinical experience, in accordance with the guidelines of the World Health Organization [32]. Intra-examiner reliability (kappa coefficient) was assessed in a sample of 14 subjects during the data collection. The kappa coefficient for intra-examiner agreement was 0.90, which indicates a high level of inter-examiner agreement.

Information was collected on the location, number, and type of natural teeth, and the kind of dentures. Teeth that were sound, decayed, filled, or filled but decayed were marked as natural teeth. Teeth with grade III mobility, retained roots, or extensive crown destruction (i.e., at least three-fourths of the clinical crown destroyed) were excluded.

\section{Statistical analysis}

We explored the relationships among the variables using STATA version 13.0 (Stata Corp, College Station, Texas USA), with the significance level set at 5\%. Continuous variables and categorical variables are expressed as mean \pm standard error (SE), counts (n), and percentages (\%), respectively.

Bivariate analysis was used to compare GOHAI-T scores with socio-demographic characteristics, dentition and denture status, dental care service usage, and factors related to denture wearing. A t-test and one-way analysis of variance were used to assess the distributions of GOHAI-T scores in relation to the categorical variables. Correlations between the GOHAI-T scores and continuous variables were evaluated using Spearman's rank correlation analysis.

The reliability of the GOHAI-T scale was evaluated using the internal consistency approach (Cronbach's alpha) in the presence and absence of each item for the subjects. Further, the convergent validity of the GOHAI-T was assessed using Spearman's rank correlation coefficient by examining the correlation between GOHAI-T scores and self-rated oral health for all subjects. The test-retest correlation coefficient for the GOHAI-T was assessed using Spearman's rank correlation coefficient by reinterviewing 30 elderly subjects 1 week after the first interview. Cronbach's alpha for internal consistency was 0.801 for the total scale and ranged between $0.764-0.813$ for each item. The relation coefficient for the GOHAI-T score and self-rated oral health was 0.356 ( $\mathrm{p}<0.0001)$. This supported the convergent validity and showed that a low GOHAI-T score, indicating a higher level of impairment of OHRQoL, was significantly associated with poor self-rated oral health. The Spearman's rank correlation coefficient for the test-retest was 0.797 ( $\mathrm{p}<.001)$, indicating an acceptable level of reliability. 
Table 1 English and Taiwanese versions of the GOHAI

\begin{tabular}{|c|c|}
\hline English questions & Taiwanese questions \\
\hline $\begin{array}{l}\text { 1. How often did you limit the kinds or } \\
\text { amounts of food you eat because of } \\
\text { problems with your teeth or dentures? }\end{array}$ & 1. 您會因為牙齒或假牙問題限制所吃的食物種類或數量嗎? \\
\hline $\begin{array}{l}\text { 2. How often did you have trouble biting or } \\
\text { chewing any kinds of food, such as firm } \\
\text { meat or apples? }\end{array}$ & 2.您有無法咀嚼食物(例如肉類或蘋果)的困擾嗎? \\
\hline $\begin{array}{l}\text { 3. How often were you able to swallow } \\
\text { comfortably? }\end{array}$ & 3.您能夠舒適的吞嚥食物嗎? \\
\hline $\begin{array}{l}\text { 4. How often have your teeth or dentures } \\
\text { prevented you from speaking the way } \\
\text { you wanted? }\end{array}$ & 4.您有因為牙齒或假牙而妨礙說話嗎? \\
\hline $\begin{array}{l}\text { 5. How often were you able to eat anything } \\
\text { without feeling discomfort? }\end{array}$ & 5.您吃任何食物時不會感到不舒服嗎? \\
\hline $\begin{array}{l}\text { 6. How often did you limit contacts with } \\
\text { people because of the condition of your } \\
\text { teeth or dentures? }\end{array}$ & 6.您會因為牙齒或假牙狀況不良而限制與人交往嗎? \\
\hline $\begin{array}{l}\text { 7. How often were you pleased or happy } \\
\text { with the looks of your teeth and gums, } \\
\text { or dentures? }\end{array}$ & 7.您對牙齒、牙齦或假牙的外觀感滿意或愉快嗎? \\
\hline $\begin{array}{l}\text { 8. How often did you use medication to } \\
\text { relieve pain or discomfort from around } \\
\text { your mouth? }\end{array}$ & 8.您使用藥物減緩口腔的疼痛或不適嗎? \\
\hline $\begin{array}{l}\text { 9. How often were you worried or } \\
\text { concerned about the problems with your } \\
\text { teeth, gums, or dentures? }\end{array}$ & 9.您擔慮或關心牙齒、牙齦或假牙的問題嗎? \\
\hline $\begin{array}{l}\text { 10. How often did you feel nervous or } \\
\text { self-conscious because of problems with } \\
\text { your teeth, gums, or dentures? }\end{array}$ & 10.您因為牙齒、牙齦或假牙問題,感到緊張或不自在、不舒適嗎? \\
\hline $\begin{array}{l}\text { 11. How often did you feel uncomfortable } \\
\text { eating in front of people because of } \\
\text { problems with your teeth or dentures? }\end{array}$ & 11.您會因為牙齒或假牙問題,在別人面前吃東西感覺到不自在嗎? \\
\hline $\begin{array}{l}\text { 12. How often were your teeth or gums } \\
\text { sensitive to hot, cold, or sweets? }\end{array}$ & 12.您的牙齒或牙龈, 對冷、熱或甜的食物會感覺敏感嗎? \\
\hline
\end{tabular}

The answers of questions were scored by 5=always(總是)，4=usually(經常)，3=occasionally(偶爾)，2=seldom(很少), and 1=never(從不). The scores were reversed in the $3 \mathrm{rd}, 7$ th and 12 th questions.

The internal consistency of the DSA (Cronbach's alpha) was assessed in the presence and absence of each item for the subjects. Cronbach's alpha was 0.887 for the total scale and ranged between $0.857-0.881$ for each item, indicating that the DSA had highly acceptable reliability. The convergent validity of the DSA was assessed using Spearman's rank correlation coefficient by examining the correlation between total denture satisfaction scores and the general satisfaction of the sample subjects. The Spearman's rank relation coefficient was 0.7583 ( $\mathrm{p}<0.001)$, which supported the convergent validity and showed that a high total denture satisfaction score was significantly associated with good general denture satisfaction.

Our data indicated that the skewness and kurtosis of GOHAI-T distribution were -0.77 and 3.25 , respectively, and that these values were more normalized than the square-root-transformed GOHAI-T distribution (skewness = -1.02 and kurtosis $=3.89$ ) or log-transformed GOHAI-T distribution (skewness $=-1.07$ and kurtosis $=4.81$ ). Hence, the raw GOHAI-T scores were chosen for multiple linear regression analysis. Moreover, we conducted a robust linear regression to confirm the analysis results and found that all the 
statistically significant variables in the results of the robust regression were the same as those obtained using general multiple linear regression. Robust regression methods are designed such that they are not overly affected by violations of assumptions by the underlying data-generating process [33].

To assess the impacts of different blocks of predictors on OHRQoL, we conducted hierarchical multiple regression analysis using all independent predictors, with variance inflation factors under 5 to avoid multicollinearity in the whole model. The analysis was performed to determine the most predictive block of variables based on the GOHAI-T scores. The GOHAI-T score was used as a dependent variable and the blocks of independent variables were entered in the following steps: Step 1: socio-demographic characteristics, Step 2: dentition and denture status, Step 3: dental care service usage, Step 4: factors related to denture wearing. $R^{2}$ shows the percentage of variability in the dependent variable that can be accounted for by all predictors. The change in $R^{2}$ can be used to measure the amount of predictive power added to the model by the addition of another block of variables in the next step. We compared the standardized regression coefficients of independent variables to determine their impact on the GOHAI-T scores.

\section{Results}

The basic characteristics of the study population are presented in Table 2. Data were collected from 277 subjects who wore removable dentures. More than half of them were women $(52.7 \%)$, the mean age ( \pm standard error) was $76.8( \pm 0.4)$ years, two-thirds had a level of education of high school or above (67.9\%), the majority were living with others $(81.2 \%)$, and more than three-fourths were able to afford their living expenses (78.7\%). Further, the mean number of natural teeth was $7.8 \pm 0.4$. The distribution of the denture status was as follows: full-mouth complete denture, $24.9 \%$; single complete denture, $24.9 \%$; single partial denture, 24.6\%; and full-mouth partial denture, 25.6\%. Those who had regular dental checkups, treatment during toothache, and dental visits in the last year accounted for $22.4 \%, 10.8 \%$, and $39.4 \%$ of the population, respectively. Regarding factors related to denture wearing, 24 (8.7\%) subjects always/often presented with oral pain, $51(18.4 \%)$ perceived that they had a loose denture, 28 (10.1\%) had an oral ulcer, 21 (7.6\%) had perceived halitosis, 31 (11.2\%) had perceived dry mouth, and the total denture satisfaction score was $19.0 \pm 0.3$. In terms of the OHRQoL, the mean ( \pm standard error) scores of the GOHAI-T subscales of PF, PSF, and PD were $47.8 \pm 0.5$, $14.3 \pm 0.2,20.8 \pm 0.3$, and $12.7 \pm 0.1$, respectively.

Gender, education level, living status, ability to afford living expenses, denture status, regular dental checkups, treatment during toothache, and dental visits in the last year were not significantly associated with PF, PSF, PD,
Table 2 Participants' characteristics $(N=277)$

\begin{tabular}{lcc}
\hline Variables & $\mathbf{n}$ & $\%$ \\
\hline Socio-demographic characteristics & & \\
Gender & 131 & 47.3 \\
$\quad$ Male & 146 & 52.7 \\
$\quad$ Female & & \\
Age (years) & 79 & 28.5 \\
65-69 & 106 & 38.3 \\
$70-79$ & 92 & 33.2 \\
$\geq 80$ & $76.8 \pm 0.4(65-90)$ & \\
$\quad$ Mean \pm SE (range) & & \\
Education level & 89 & 32.1 \\
Less than high school & 188 & 67.9 \\
High school or above & & \\
Living status & 52 & \\
Alone & 225 & \\
With others & & 21.3 \\
Able to afford living expenses & 218 & \\
Yes & 59 & \\
No & &
\end{tabular}

Dentition and denture status

Remaining natural teeth

Mean $\pm S E$ (range)

$7.78 \pm 0.4(0-26)$

Denture status

Full-mouth complete denture

Single complete denture

Single partial denture

Full-mouth partial denture

24.6

Dental care service usage

Regular dental checkups

Treatment during toothache

Dental visits in the last year

Factors related to denture wearing

Presence of oral pain

Perceived loose denture

Presence of oral ulcer

Perceived halitosis

71

Perceived dry mouth

Total denture satisfaction scores

Mean \pm SE (range)

$19.0 \pm 0.3(6-30)$

Oral health related quality of life

Mean \pm SE (range)

GOHAl-T scores

$47.8 \pm 0.5(22-60)$

Physical function

$14.3 \pm 0.2(4-20)$

Psychosocial function

$20.8 \pm 0.3(5-25)$

$12.7 \pm 0.1(3-15)$ 
and total GOHAI-T scores. However, subjects who had oral pain, perceived that they had a loose denture, had an oral ulcer, and perceived that they had halitosis had lower PF and total GOHAI-T scores. Further, those who had perceived dry mouth had lower GOHAI-T scores (Table 3).

Denture satisfaction scores were positively associated with PF, PSF, PD, and GOHAI-T scores. We also found that the PF and PSF scores were significantly lower for subjects with a lower number of natural teeth. However, age was not significantly correlated with PF, PSF, PD, and total GOHAI-T scores (Table 4).

Hierarchical multiple regression was performed to investigate the ability of factors related to denture wearing to predict GOHAI-T scores, after controlling for sociodemographic variables, dentition and denture status, and dental care service usage. Socio-demographic characteristics were entered in Model I and this model was not statistically significant, $\mathrm{F}(5,271)=1.99, \mathrm{p}>0.05$. We added dentition and denture status to the socio-demographic characteristics in Model II, and the model as a whole explained a total of $12.4 \%$ of the variance, $F(9,267)=4.20, p<.001$. The education level, number of natural teeth, and denture status were predictors of GOHAI-T scores. In Model III, factors related to denture wearing were added, and the total variance explained by the model as a whole increased to $52.4 \%, \mathrm{~F}(15,261)=19.13, \mathrm{p}<0.001$. The introduction of factors related to denture wearing explained an additional $40.0 \%$ of the variance in GOHAI-T scores, $\Delta R^{2}=0.40, \mathrm{~F}(6,261)=$ $36.50, \mathrm{p}<0.001$. Dental care service usage was added in Model IV, and the total variance explained by the model was $53.3 \%, \mathrm{~F}(18,258)=16.3, \mathrm{p}<0.001$. The introduction of dental care service usage explained an additional $0.9 \%$ of the variance in GOHAI-T scores, $\Delta R^{2}=0.009, \mathrm{~F}(3,258)=1.68, \mathrm{p}>$ 0.05 . In the final model, 6 of 18 predictor variables were statistically significant, with denture satisfaction having a higher beta value $(\beta=0.45, \mathrm{p}<.001)$ than the remaining natural teeth $(\beta=0.26, p<.001)$, denture status, perceived loose denture, presence of oral ulcer, and educational level (Table 5).

\section{Discussion}

Despite the important findings, our study had several limitations that should be considered with some caution when interpreting the results. First, we did not use a populationbased sample, but a convenience sample from the Senior Citizens' College of Kaohsiung City, and thus, our study represents only a subgroup of the public. Future research should focus on generalizing the findings to the elderly Taiwanese people wearing removable dentures. Second, the present study is characterized by a cross-sectional design, and therefore, we cannot make inferences with respect to the direction of the observed associations. The third limitation was related to the study instrument. Because no a Chinese version of the GOHAI for Taiwanese had been validated when the study was performed, the original English version was translated by the researchers and was examined among a convenience sample of elderly subjects in Kaohsiung City for its construct validity and internal reliability. Therefore, further studies may be required to determine whether this version can be applied to the elderly Taiwanese population.

To enable the development of patient-oriented approaches in public health care and provide appropriate oral health care to elderly people wearing removable dentures, it is important to know which predictors actually affect the OHRQoL of elderly people. Therefore, the present study aimed to assess the factors of OHRQoL among elderly people wearing removable denture. Results of the hierarchical multiple regression showed that factors related to denture wearing were most strongly associated with OHRQoL, with denture satisfaction being the strongest predictor of OHRQoL, and the number of remaining natural teeth was the second highest predictor. In addition, the OHRQoL of elderly people wearing removable dentures could also be predicted by education level, denture status, perceived loose denture, and presence of oral ulcer. Thus, among the predictors analyzed in this study, denture satisfaction was the best predictor of OHRQoL of elderly people wearing removable dentures.

The findings of this study suggested that high satisfaction with removable dentures was significantly related to a high GOHAI-T score, indicating a low level of impairment of OHRQoL. This is in line with the findings of previous studies that showed a positive correlation between self-reported denture satisfaction and OHRQoL in the elderly [23]. In their 2-year longitudinal analysis, Stober et al. [19] showed that elderly patients' satisfaction with complete dentures was associated with OHRQoL, based on scores on the shortened version of the OHIP. Recently, Kuo et al. [7] reported that patients' satisfaction with complete dentures was significantly related to an improvement in their OHRQoL, as measured using the OHIP-14. In their cross-sectional analysis, Lee et al. [10] showed that if the elderly are satisfied with their dentures, OHRQoL, assessed using the OHIP, may be unaffected by oral health problems.

A recent study described a positive correlation between professional ratings of removable denture quality and a low OHIP score, indicating a low level of impairment of OHRQoL [29]. However, a poorly fitting denture may be well tolerated in one person, while a well fitting denture may create problems for another [30]. Garrett et al. [34] reported that 55\% of 21 patients with poorly fitting denture [31] had moderate-to-complete denture satisfaction, which was found by the examining dentists assessing need for denture replacement. Närhi et al. [35] found a weak or statistically nonsignificant correlation between patients' denture satisfaction and clinical measurements such as anatomic conditions, as 
Table 3 Oral health-related quality of life in denture-wearing elderly subjects $(N=277)$

\begin{tabular}{|c|c|c|c|c|}
\hline Variables & $\begin{array}{l}\text { Physical function } \\
\text { (Maximum score = 20) } \\
\text { Mean } \pm \text { SE }\end{array}$ & $\begin{array}{l}\text { Psychosocial function } \\
\text { (Maximum score }=25 \text { ) } \\
\text { Mean } \pm \text { SE }\end{array}$ & $\begin{array}{l}\text { Pain and discomfort } \\
\text { (Maximum score }=15 \text { ) } \\
\text { Mean } \pm \text { SE }\end{array}$ & $\begin{array}{l}\text { GOHAI-T scores } \\
(\text { Maximum score }=60) \\
\text { Mean } \pm \text { SE }\end{array}$ \\
\hline \multicolumn{5}{|l|}{ Gender } \\
\hline Male & $14.37 \pm 0.31$ & $20.86 \pm 0.36$ & $12.84 \pm 0.16$ & $48.08 \pm 0.67$ \\
\hline Female & $14.18 \pm 0.32$ & $20.66 \pm 0.37$ & $12.61 \pm 0.19$ & $47.44 \pm 0.72$ \\
\hline \multicolumn{5}{|l|}{ Education level } \\
\hline Less than high school & $14.16 \pm 0.27$ & $20.53 \pm 0.31$ & $12.63 \pm 0.15$ & $47.32 \pm 0.60$ \\
\hline High school or above & $14.53 \pm 0.37$ & $21.26 \pm 0.46$ & $12.94 \pm 0.23$ & $48.73 \pm 0.84$ \\
\hline \multicolumn{5}{|l|}{ Living status } \\
\hline Alone & $14.01 \pm 0.24$ & $20.60 \pm 0.29$ & $12.68 \pm 0.14$ & $47.30 \pm 0.55$ \\
\hline With others & $15.42 \pm 0.49$ & $21.46 \pm 0.53$ & $12.96 \pm 0.30$ & $49.85 \pm 1.03$ \\
\hline \multicolumn{5}{|l|}{ Able to afford living expenses } \\
\hline Yes & $14.39 \pm 0.25$ & $20.92 \pm 0.28$ & $12.89 \pm 0.13$ & $48.20 \pm 0.53$ \\
\hline No & $13.88 \pm 0.48$ & $20.20 \pm 0.63$ & $12.14 \pm 0.33$ & $46.22 \pm 1.18$ \\
\hline \multicolumn{5}{|l|}{ Denture status } \\
\hline Full-mouth complete denture & $13.91 \pm 0.41$ & $20.67 \pm 0.63$ & $13.23 \pm 0.23$ & $47.81 \pm 1.05$ \\
\hline Single complete denture & $13.29 \pm 0.44$ & $19.99 \pm 0.54$ & $12.26 \pm 0.27$ & $45.54 \pm 1.00$ \\
\hline Single partial denture & $14.41 \pm 0.48$ & $21.06 \pm 0.44$ & $12.47 \pm 0.26$ & $47.94 \pm 0.97$ \\
\hline Full-mouth partial denture & $15.46 \pm 0.41$ & $21.34 \pm 0.42$ & $12.96 \pm 0.24$ & $49.76 \pm 0.85$ \\
\hline \multicolumn{5}{|l|}{ Regular dental checkups } \\
\hline No & $14.04 \pm 0.25$ & $20.78 \pm 0.30$ & $12.73 \pm 0.14$ & $47.55 \pm 0.56$ \\
\hline Yes & $15.10 \pm 0.47$ & $20.73 \pm 0.51$ & $12.73 \pm 0.28$ & $48.55 \pm 1.04$ \\
\hline \multicolumn{5}{|l|}{ Treatment during toothache } \\
\hline No & $14.35 \pm 0.24$ & $20.81 \pm 0.26$ & $12.69 \pm 0.14$ & $47.85 \pm 0.52$ \\
\hline Yes & $13.67 \pm 0.61$ & $20.43 \pm 0.98$ & $13.07 \pm 0.32$ & $47.17 \pm 1.47$ \\
\hline \multicolumn{5}{|l|}{ Dental visits in the last year } \\
\hline No & $13.99 \pm 0.30$ & $20.34 \pm 0.34$ & $12.54 \pm 0.16$ & $46.88 \pm 0.66$ \\
\hline Yes & $14.72 \pm 0.32$ & $21.42 \pm 0.39$ & $13.03 \pm 0.20$ & $49.17 \pm 0.71$ \\
\hline \multicolumn{5}{|l|}{ Presence of oral pain } \\
\hline No & $14.56 \pm 0.23^{*}$ & $21.11 \pm 0.24$ & $12.88 \pm 0.13$ & $48.55 \pm 0.48^{*}$ \\
\hline Yes & $11.29 \pm 0.57$ & $17.13 \pm 1.42$ & $11.21 \pm 0.53$ & $39.63 \pm 1.90$ \\
\hline \multicolumn{5}{|l|}{ Perceived loose denture } \\
\hline No & $15.06 \pm 0.22^{*}$ & $21.56 \pm 0.22$ & $12.97 \pm 0.14$ & $49.59 \pm 0.45^{*}$ \\
\hline Yes & $10.80 \pm 0.41$ & $17.24 \pm 0.87$ & $11.69 \pm 0.29$ & $39.73 \pm 1.28$ \\
\hline \multicolumn{5}{|l|}{ Presence of oral ulcer } \\
\hline No & $14.61 \pm 0.23^{*}$ & $21.33 \pm 0.22$ & $12.94 \pm 0.12$ & $48.89 \pm 0.46^{*}$ \\
\hline Yes & $11.29 \pm 0.61$ & $15.75 \pm 1.26$ & $10.86 \pm 0.46$ & $37.89 \pm 1.71$ \\
\hline \multicolumn{5}{|l|}{ Perceived halitosis } \\
\hline No & $14.53 \pm 0.22^{*}$ & $20.96 \pm 0.26$ & $12.82 \pm 0.13$ & $48.32 \pm 0.49^{*}$ \\
\hline Yes & $11.19 \pm 0.74$ & $18.33 \pm 1.17$ & $11.67 \pm 0.60$ & $41.19 \pm 1.90$ \\
\hline \multicolumn{5}{|l|}{ Perceived dry mouth } \\
\hline No & $14.46 \pm 0.23$ & $21.16 \pm 0.24$ & $12.83 \pm 0.13$ & $48.45 \pm 0.47^{*}$ \\
\hline Yes & $13.00 \pm 0.69$ & $17.91 \pm 1.10$ & $12.03 \pm 0.42$ & $42.94 \pm 1.95$ \\
\hline
\end{tabular}

The $p$ value was calculated by one-way analysis of variance for denture status and by two sample t-tests for the other factors. ${ }^{*} p<0.05$. 
Table 4 Correlations among oral health-related quality of life, age, and denture-related factors $(N=277)$

\begin{tabular}{|c|c|c|c|c|}
\hline Variables & $\begin{array}{l}\text { Physical function } \\
\text { (Maximum score }=20 \text { ) } \\
\text { Coefficients }\end{array}$ & $\begin{array}{l}\text { Psychosocial function } \\
\text { (Maximum score }=25 \text { ) } \\
\text { Coefficients }\end{array}$ & $\begin{array}{l}\text { Pain and discomfort } \\
\text { (Maximum score }=15 \text { ) } \\
\text { Coefficients }\end{array}$ & $\begin{array}{l}\text { GOHAI-T score } \\
\text { (Maximum score }=60 \text { ) } \\
\text { Coefficients }\end{array}$ \\
\hline Age (years) & 0.01 & -0.05 & 0.09 & 0.01 \\
\hline Remaining natural teeth & $0.17^{*}$ & $0.25^{*}$ & 0.06 & 0.03 \\
\hline Total denture satisfaction scores & $0.65^{*}$ & $0.55^{*}$ & $0.56^{*}$ & $0.45^{*}$ \\
\hline Satisfaction with chewing ability & $0.54^{*}$ & $0.49^{*}$ & $0.43^{*}$ & $0.35^{*}$ \\
\hline Satisfaction with ability to speak clearly & $0.56^{*}$ & $0.47^{*}$ & $0.49^{*}$ & $0.38^{*}$ \\
\hline Satisfaction with appearance & $0.43^{*}$ & $0.31^{*}$ & $0.43^{*}$ & $0.29^{*}$ \\
\hline Satisfaction with tasting ability & $0.49^{*}$ & $0.44^{*}$ & $0.40^{*}$ & $0.31^{*}$ \\
\hline $\begin{array}{l}\text { Satisfaction with retention of } \\
\text { dentures (total,estimate) }\end{array}$ & $0.50^{*}$ & $0.43^{*}$ & $0.40^{*}$ & $0.35^{*}$ \\
\hline Satisfaction with comfort (total, estimate) & $0.52^{*}$ & $0.40^{*}$ & $0.47^{*}$ & $0.40 *$ \\
\hline
\end{tabular}

${ }^{*} \mathrm{p}<0.05$.

well as denture quality. Thus, denture satisfaction is not based on the technical quality of the dentures alone. Moreover, Turker et al. [30] suggested that although patients seek technical advice, psychological and emotional factors play an important role in their poor adaptation to the denture. Another study showed that the dentistpatient relationship and psychological factors had a great impact on patients' acceptance of and adaptation to removable dentures [33]. Therefore, in addition to clinical and technical skills, gaining a better understanding of patient behavior and psychology, and improving communication are crucial to improving patients' denture satisfaction [30,33].

In the present study, subjects with a perceived loose denture gained significantly lower mean GOHAI-T scores, indicating a worse OHRQoL than those without a perceived loose denture. This result is in accordance with those of previous studies [23] showing that denture loosening was a significant contributing factor to low OHRQoL. Moreover, Hassel et al. [11] showed that improving retention of previously insufficiently retained dentures was positively associated with OHRQoL, as measured using the OHIP-49 (German version), among removable denture wearers. Hassel et al. further indicated that denture loosening affects many aspects of quality of life, both psychological and social. Komagamine et al. [22] also reported that sufficient retention of lower dentures is important to improving OHRQoL in edentulous patients. Hence, it is necessary to identify and improving retention of previously insufficiently retained dentures in order to improve the OHRQoL of elderly persons wearing removable dentures.

Removable dentures can injure oral tissues, and their use is associated with a high frequency of oral mucosal lesions [36]. In the present study, subjects who had had an oral ulcer were more likely to report a poorer
OHRQoL than their counterparts without oral ulcer experiences. This finding is consistent with the results of many previous studies showing that oral ulcers were associated with a poor OHRQoL [37]. In a study evaluating the sensitivity of patient-centered outcome measures to treatment, McGrath et al. [34] suggested that patients with ulcers and symptomatic oral mucosal lesions had poorer OHRQoL (measured using the OHIP-14) than their counterparts with non-symptomatic lesions. Recently, Suliman et al. [13] showed that oral ulcerative lesions were significantly associated with oral impacts on daily performance, indicating poor quality of life. Moreover, Mandali et al. [38] suggested that recall visits and shortened denture usage are essential for prevention of oral mucosal lesions. Therefore, to improve OHRQoL of elderly population, it is important to educate and regularly review patients who wear dentures with regard to oral tissue injuries.

Our results demonstrated that the number of remaining natural teeth was positively associated with OHRQoL; thus, the larger the number of remaining natural teeth, the lower the impact on the OHRQoL. This result was in accordance with those of many previous studies $[12,16]$. Zaitsu et al. [17] suggested that the number of missing teeth was significantly associated with low GOHAI scores, indicating a poor OHRQoL. In their metaanalysis, Gerritsen et al. [18] showed that tooth loss is associated with impairment of OHRQoL, and this association seems to be independent of the OHRQoL assessment instrument used and the context of the included samples. Moreover, Jain et al. [12] indicated that a decrease in the number of remaining natural teeth was correlated with poor OHRQoL, independent of the effect of age and gender. Therefore, they concluded that all populations with complete natural dentition show a good OHRQoL. 
Table 5 Hierarchical multiple regression analysis of GOHAI-T scores

\begin{tabular}{|c|c|c|c|c|c|c|c|c|c|c|c|c|}
\hline \multirow[t]{2}{*}{ Block and variables } & \multicolumn{3}{|c|}{ Model I } & \multicolumn{3}{|c|}{ Model II } & \multicolumn{3}{|c|}{ Model III } & \multicolumn{3}{|c|}{ Model IV } \\
\hline & B & $\beta$ & $\mathbf{t}$ & B & $\beta$ & $\mathbf{t}$ & B & $\beta$ & 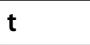 & B & $\beta$ & $\mathbf{t}$ \\
\hline \multicolumn{13}{|c|}{ Socio-demographic characteristics } \\
\hline Age & 0.03 & 0.02 & 0.31 & 0.10 & 0.08 & 1.28 & 0.07 & 0.05 & 1.11 & 0.06 & 0.04 & 0.94 \\
\hline \multicolumn{13}{|l|}{ Gender } \\
\hline Female vs. male & 0.01 & 0.00 & 0.01 & 0.01 & 0.00 & 0.01 & 0.52 & 0.03 & 0.67 & 0.71 & 0.04 & 0.90 \\
\hline \multicolumn{13}{|l|}{ Education level } \\
\hline $\begin{array}{l}\text { Lower than high school vs. } \\
\text { high school or above }\end{array}$ & 1.51 & 0.09 & 1.33 & 2.56 & 0.15 & $2.29^{*}$ & 1.93 & 0.11 & $2.32^{*}$ & 1.92 & 0.11 & $2.28^{*}$ \\
\hline \multicolumn{13}{|l|}{ Living alone } \\
\hline Yes vs. no & 2.53 & 0.12 & $1.98^{*}$ & 2.26 & 0.11 & 1.82 & 1.73 & 0.08 & 1.87 & 1.55 & 0.07 & 1.66 \\
\hline \multicolumn{13}{|l|}{ Able to afford living expenses } \\
\hline No vs. yes & -2.60 & -0.13 & $-2.13^{*}$ & -2.27 & -0.11 & -1.92 & -1.26 & -0.06 & -1.43 & -1.39 & -0.07 & -1.55 \\
\hline \multicolumn{13}{|l|}{ Dentition and denture status } \\
\hline Remaining natural teeth & & & & 0.41 & 0.36 & $3.72^{* *}$ & 0.24 & 0.21 & $2.87^{* *}$ & 0.29 & 0.26 & $3.34^{* *}$ \\
\hline \multicolumn{13}{|l|}{ Denture status } \\
\hline Single CD vs. CD & & & & -5.07 & -0.27 & $-3.47^{* *}$ & -2.54 & -0.14 & $-2.28^{*}$ & -2.24 & -0.12 & -1.94 \\
\hline Single RPD vs. CD & & & & -3.47 & -0.18 & $-2.17^{*}$ & -3.18 & -0.17 & $-2.60^{*}$ & -3.07 & -0.16 & $-2.47^{*}$ \\
\hline Full-mouth RPD vs. CD & & & & -4.43 & -0.24 & -2.04 & -2.59 & -0.14 & -1.57 & -2.52 & -0.13 & -1.52 \\
\hline
\end{tabular}

\section{Factors related to denture wearing}

Presence of oral pain

(always/often)

Yes vs. no

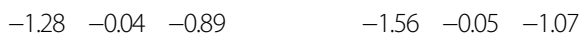

Perceived loose denture

(always/often)

Yes vs. no

$-3.12-0.15-2.84^{* *} \quad-3.50-0.17-3.15^{* *}$

Presence of oral ulcer

(always/often)

Yes vs. no

$-4.83-0.18-3.46^{* *} \quad-4.23-0.16-2.97^{* *}$

Perceived halitosis

(always/often)

Yes vs. no

$\begin{array}{llllll}-1.74 & -0.06 & -1.23 & -1.90 & -0.06 & -1.35\end{array}$

Perceived dry mouth

(always/often)

Yes vs. no

Total denture satisfaction

scores

$\begin{array}{llllll}-1.88 & -0.08 & -1.61 & -2.00 & -0.08 & -1.71 \\ 0.77 & 0.44 & 8.79^{* *} & 0.79 & 0.45 & 8.85^{* * *}\end{array}$

Dental care service usage

Regular dental checkups

No vs. yes

$-1.77-0.09-1.86$

Treatment during toothache

$$
\text { No vs. yes }
$$$$
\begin{array}{lll}
1.52 & 0.06 & 1.16
\end{array}
$$

Dental visits in the last year

\begin{tabular}{|c|c|c|c|c|c|}
\hline No vs. yes & & & & $-0.18-0.01$ & -0.22 \\
\hline$\overline{R^{2}}$ & 0.035 & $0.124^{* * * *}$ & $0.524^{* * * *}$ & & $0.533^{* * *}$ \\
\hline Adjusted $R^{2}$ & 0.018 & $0.094^{* * *}$ & $0.496^{* * *}$ & & $0.500^{* * *}$ \\
\hline$F(d f 1, d f 2)$ & $F(5,271)=1.99$ & $F(9,267)=4.20$ & $F(15,261)=19.13$ & & $F(18,258)=16.35$ \\
\hline$p$ & 0.081 & 0.000 & 0.000 & & 0.000 \\
\hline
\end{tabular}


Table 5 Hierarchical multiple regression analysis of GOHAI-T scores (Continued)

\begin{tabular}{lllll}
\hline$\Delta R^{2}$ & 0.035 & $0.089^{* * * *}$ & $0.400^{* * *}$ & 0.009 \\
$F$ change & $F(5,271)=1.99$ & $F(4,267)=6.75$ & $F(6,261)=36.50$ & $F(3,258)=1.68$ \\
p for F change & 0.081 & 0.000 & 0.0000 & 0.172 \\
\hline
\end{tabular}

Hierarchical multiple regression for the association between GOHAI-T scores and all block variables with VIF set at $<5$ to avoid multicollinearity.

$\Delta R^{2}$ : change in $R^{2}$; statistical significance: ${ }^{*} \mathrm{p}<0.05,{ }^{* *} \mathrm{p}<0.01,{ }^{* * *} \mathrm{p}<0.001$.

Model I: Block1 (socio-demographic variables).

Model II: Block1 (socio-demographic variables) + block 2 (dentition and denture status).

Model III: Block1 (socio-demographic variables) + block 2 (dentition and denture status) + block 3 (factors related to denture wearing).

Model IV: Block1 (socio-demographic variables) + block 2 (dentition and denture status) + block 3 (factors related to denture wearing) + block 4 (dental care service usage).

Our study also showed that denture status was a predictor of OHRQoL, as measured by the GOHAI-T, and that removable partial denture (RPD) wearers experienced a more adverse impact of the dentures on their OHRQoL than did complete denture wearers. Another study found that RPD users experienced impaired OHRQoL more often than did CD users, based on responses to the OHIP [39]. In addition, Wong et al. [21] reported that in a sample of community-dwelling elderly Chinese people, those who wore RPD experienced a greater OHRQoL impairment (measured by the GOHAI) than did CD wearers. These findings probably result from the unrealistic expectations of the wearers from their dentures, i.e., RPD wearers tend to compare their dentures with natural teeth. In contrast, researchers have shown that CD wearers have usually previously used RPD and might accept the lack of teeth and oral discomfort as a part of the aging process. Thus, CD wearers might be more accepting of the limitations of denture functions than RPD wearers are $[22,39]$.

In our study, educational level had a significant influence on GOHAI-T scores. Subjects with a higher education level were more likely to have poorer OHRQoL, indicating more perceived dental problems in this group than in those with an education level lower than high school. A possible explanation for this trend may be related to a person's expectations. Subjects with a lower level of education may have lower standards or expectations in their evaluation of health satisfaction or life satisfaction and, accordingly, be more likely to be satisfied than those who are more highly educated [40]. Another possible reason is that subjects with a higher education level may be more concerned about problems with oral health and esthetics than those with a lower education level are, as this may be less accepted in the social circles of those who are more highly education. Therefore, those with a lower education level and lower expectations may report higher GOHAI-T scores, indicating a better OHRQoL.

Compared to other international literature dealing with OHRQoL in the elderly, we found lower GOHAI-T values in this study. One possible reason for this is that the subjects in this study were elderly individuals wearing removable dentures. Hogenius et al. [8] showed that compared to people with natural teeth, those who wear removable dentures experience more significant negative impacts on social and emotional aspects of life. Another possible reason may be that the subjects in this study were sourced from the Government Senior Citizens' Service Center in Taiwan. Elderly people attending this center tend to have a higher education level and better socioeconomic status. Subjects with a higher level of education may have higher expectations relating to their oral health satisfaction and, accordingly, be more likely to have lower GOHAI-T values [15].

The present study was performed in 2009, at which time the GOHAI had not yet been translated for use in Taiwan. A Chinese version of the GOHAI for older people living in Hong Kong and southern China was developed in 2002 [41]. Though the Taiwanese language is influenced by Chinese culture, there are a number of differences between the spoken and written Chinese of Hong Kong and that of Taiwan, so, the wording of the questions in the Chinese version of the GOHAI could confuse elderly Taiwanese individuals. Therefore, in the current study, we did not use the Chinese version of the GOHAI for assessing OHRQoL measures. Instead, a Chinese version of the GOHAI for use with Taiwanese people specifically (GOHAI-T) was developed.

A strength of the current study was that we simultaneously controlled both for factors related to denture wearing and for relevant influencing factors mentioned in previous similar studies. In the final model, the overall explanatory power was 0.533 . The present findings confirmed that factors related to denture wearing were most strongly associated with OHRQoL, with denture satisfaction being the strongest predictor. Therefore, in clinical praxis, denture satisfaction is a useful tool to evaluate the effect of denture treatment on OHRQoL. However, a weakness of the study was that the nature of the causality in which denture satisfaction is used to predict OHRQoL was still unclear due to the cross-sectional design. Therefore, OHRQoL could not be measured by the total denture satisfaction score instead of the GOHAI-T score.

\section{Conclusions}

In conclusion, of the factors analyzed in this study, those related to denture wearing were most strongly associated 
with OHRQoL, and denture satisfaction was the strongest predictor among them. It is suggested that denture satisfaction is useful as a tool for assessing the effect of denture treatment on the OHRQoL of elderly individuals wearing removable dentures.

\section{Abbreviations}

OHRQoL: Oral health-related quality of life; OHIP: Oral health impact profile; DSA: Denture-satisfaction assessment; PD: Pain or discomfort; PF: Physical function; PSF: Psychosocial function; NT: Natural teeth; GOHAl: Geriatric oral health assessment index

\section{Competing interests}

The authors declare that they have no competing interests.

\section{Authors' contributions}

Y-YY contributed to the study design, data collection, statistical analysis and revision of the manuscript. $\mathrm{K}-\mathrm{JH}$ conceived the study design and conducted the clinical examination, data collection, drafting and revision of the manuscript. H-EL, Y-MW, and S-JL was responsible for interpretation and collection of the data. W-CW, J-K D, and S-TH was involved inthe study design and revised the manuscript. All authors read and approved the final manuscript.

\section{Acknowledgements}

Thanks to personnel at the Kaohsiung City Government Senior Citizens' Service, for administrational and venue support and to senior students of Department of Oral Hygiene, Kaohsiung Medical University, for their help interviewing questionnaires. The study was funded by College of Dental Medicine, Kaohsiung Medical University.

\begin{abstract}
Author details
'Department of Oral Hygiene, College of Dental Medicine, Kaohsiung Medical University, Kaohsiung, Taiwan. ${ }^{2}$ School of Dentistry, College of Dental Medicine, Kaohsiung Medical University, Kaohsiung, Taiwan. ${ }^{3}$ Division of Prosthodontics, Department of Dentistry, Kaohsiung Medical University Hospital, Kaohsiung, Taiwan. ${ }^{4}$ Division of Periodontics, Department of Dentistry, Kaohsiung Medical University Hospital, Kaohsiung, Taiwan. ${ }^{5}$ Department of Healthcare Administration, College of Health Science, Asia University, Taichung, Taiwan. ${ }^{6}$ Division of Oral Pathology, Department of Dentistry, Kaohsiung Medical University Hospital, Kaohsiung, Taiwan. ${ }^{7}$ Department of Dentistry, Kaohsiung Municipal Ta-Tung Hospital, Kaohsiung, Taiwan. ${ }^{8}$ Division of Pediatric Dentistry, Department of Dentistry, Kaohsiung Medical University Hospital, Kaohsiung, Taiwan. ${ }^{9}$ Division of Family Dentistry, Department of Dentistry, Kaohsiung Medical University Hospital, Kaohsiung, Taiwan. ${ }^{10}$ Department of Dentistry, Kaohsiung Municipal Ci-Jin Hospital, Kaohsiung, Taiwan.
\end{abstract}

Received: 3 August 2014 Accepted: 22 December 2014 Published: 5 January 2015

\section{References}

1. United states Census Bureau, International Data Base, Fertility Rates - Custom Region - Taiwan. http://www.census.gov/population/international/data/ idb/region.php? $\mathrm{N}=\% 20$ Results\%20\&T=9\&A=separate\&RT $=0 \& \mathrm{Y}=2010 \& R=-$ 1\&C=TW. Accessed 12 April 2014

2. United states Census Bureau, International Data Base, Mid-year Population by Older Age Groups and Sex - Custom Region - Taiwan. .http://www.census. gov/population/international/data/idb/region.php? $\mathrm{N}=\% 20$ Results\%20\&T=2\&A= separate\&RT=0\&Y=2026\&R=-1\&C=TW. Accessed 12 April 2014.

3. World Health Organization (WHO). "Frequently asked questions: what is WHO's definition of health?". Available at http://wwwwhoint/kobe_centre/ about/faq/en/. Accessed 09 September 2012.

4. Atchison KA, Dolan TA. Development of the geriatric oral health assessment Index. J Dent Educ. 1990:54:680-7.

5. Heydecke G, Locker D, Awad MA, Lund JP, Feine JS. Oral and general health-related quality of life with conventional and implant dentures. Community Dent Oral Epidemiol. 2003;31:161-8.

6. Carlsson GE, Omar R. The future of complete dentures in oral rehabilitation. A critical review. J Oral Rehabil. 2010;37:143-56.
7. Kuo HC, Kuo YS, Lee IC, Wang JC, Hsin YY. The association of responsiveness in oral and general healthrelated quality of life with patients'satisfaction of new complete dentures. Qual Life Res. 2013;22:1665-74.

8. Hogenius S, Berggren U, Blomberg G, Jemt T, Ohman SC. Demographical, odontological, and psychological variables in individuals referred for osseointegrated dental implants. Community Dent Oral Epidemiol. 1992;20:224-8

9. Fiske J, David D, Frances C, Gelbier $S$. The emotional effects of tooth loss in edentulous people. Br Dent J. 1998;184:90-3.

10. Lee IC, Yang YH, Ho PS, Lee IC. Exploring the quality of life after denturewearing within elders in Kaohsiung. Gerodontology. 2012;29:e1067-77.

11. Hassel AJ, Koke U, Schmitter M, Rammelsberg P. Factors associated with oral health-related quality of life in institutionalized elderly. Acta Odontol Scand. 2006;64:9-15.

12. Jain M, Kaira LS, Sikka G, Singh S, Gupta A, Sharma R, et al. How Do Age and tooth loss affect oral health impacts and quality of life? a study comparing Two state samples of Gujarat and Rajasthan. J Dent. 2012;9(2):135-44.

13. Suliman NM, Johannessen AC, Ali RW, Salman H, Astrøm AN. Influence of oral mucosal lesions and oral symptoms on oral health related quality of life in dermatological patients: a cross sectional study in Sudan. Oral Health. 2012:12:19-29.

14. Astrøm AN, Haugejorden O, Skaret E. Oral impacts on daily performance in Norwegian adults: the influence of age, number of missing teeth, and socio-demographic factors. Eur J Oral Sci. 2006;114:115-21.

15. Hsu KJ, Lee HE, Wu YM, Lan SJ, Huang ST, Yen YY. Masticatory factors as predictors of oral health-related quality of life among elderly people in Kaohsiung City, Taiwan. Qual Life Res. 2014;23(4):1395-405.

16. Ekanayake L, Perera I. The association between clinical oral health status and oral impacts experienced by older individuals in Sri Lanka. J Oral Rehabil. 2004:31:831-6.

17. Zaitsu T, Ueno M, Shinada K, Ohara S, Wright FA, Kawaguchi Y. Association of clinical oral health status with self-rated oral health and GOHAl in Japanese adults. Community Dent Health. 2011;28(4):297-300.

18. Gerritsen AE, Allen PF, Witter DJ, Bronkhorst EM, Creugers NHJ. Tooth loss and oral health-related quality of life: a systematic review and meta-analysis. Health Qual Life Outcomes. 2010:8:126-36.

19. Stober T, Danner D, Lehmann F, Séché A-C, Rammelsberg P, Hassel AJ. Association between patient satisfaction with complete dentures and oral health-related quality of life: two-year longitudinal assessment. Clin Oral Investig. 2012;16:313-8.

20. John MT, Koepsell TD, Hujoel P, Miglioretti DL, LeResche L, Micheelis W. Demographic factors, denture status and oral health-related quality of life. Community Dent Oral Epidemiol. 2004:32:125-32.

21. Wong MC, MCMillan AS. Tooth loss, denture wearing and oral health-related quality of life in elderly Chinese people. Community Dent Health. 2005;22(3):156-61

22. Komagamine Y, Kanazawa M, Kaiba Y, Sato Y, Minakuchi S, Sasaki Y. Association between self-assessment of complete dentures and oral health-related quality of life. J Oral Rehabil. 2012;39:847-57.

23. Hassel AJ, Rolko C, Grossmann AC, Ohlmann B, Rammelsberg P. Correlations between self-ratings of denture function and oral health-related quality of life in different age groups. Int J Prosthodont. 2007;20:242-4.

24. Pattussi MP, Olinto MT, Hardy R, Sheiham A. Clinical, social and psychosocial factors associated with self-rated oral health in Brazilian adolescents. Community Dent Oral Epidemiol. 2007:35:377-86.

25. Buunk-Werkhoven YAB, Clercq MD-I, Verheggen-Udding EL, Jong N, Spreen M. Halitosis and oral health-related quality of life: a case report. Int J Dent Hygiene. 2012:10:3-8.

26. Inoue M, John MT, Tsukasaki H, Furuyama C, Baba K. Denture quality has a minimal effect on health-related quality of life in patients with removable dentures. J Oral Rehabil. 2011;38(11):818-26.

27. Lee IC, Shieh TY, Yang YH, Tsai CC, Wang KH. Individuals' perception of ora health and its impact on the healthrelated quality of life. J Oral Rehabil. 2007:34(2):79-87.

28. Pfeiffer E. A short portable mental status questionnaire for the assessment of organic brain deficient in elderly patients. J Am Geriatr Soc. 1975;23:433-41.

29. Inukai M, Baba K, John MT, Igarashi Y. Does removable partial denture quality affect Individuals' oral health? J Dent Res. 2008;87(8):736-9.

30. Turker SB, Sener ID, Özkan YK. Satisfaction of the complete denture wearers related to various factors. Arch Gerontol Geriatr. 2009:49:e126-9. 
31. Garrett NR, Kapur KK, Perez P. Effects of improvements of poorly fitting dentures and new dentures on patient satisfaction. J Prosthet Dent. 1996;76:403-13.

32. World Health Organization. Oral Health Survey, Basic Methods. 4th ed. Geneva: World Health Organization; 1997.

33. Carlsson GE. Clinical morbidity and sequelae of treatment with complete dentures. J Prosthet Dent. 1997;79:17-23.

34. McGrath C, Hegarty AM, Hodgson TA, Porter SR. Patient-centred outcome measures for oral mucosal disease are sensitive to treatment. Int J Oral Maxillofac Surg. 2003;32:334-6.

35. Närhi TO, Ettinger RL, Lam EW. Radiographic findings, ridge resorption, and subjective complaints of complete denture patients. Int J Prosthodont. 1997;10(2):183-9.

36. Coelho CMP, Sousa YTCS, Dare AMZ. Denture related oral mucosal lesions in a Brazilian school of dentistry. J Oral Rehabil. 2004;31:135-9.

37. Liu $L$, Xiao W, He QB, Jiang WW. Generic and oral quality of life is affected by oral mucosal diseases. BMC Oral Health. 2012;12:2.

38. Mandali G, Sener ID, Turker SB, Ülgen H. Factors affecting the distribution and prevalence of oral mucosal lesions in complete denture wearers. Gerodontology. 2011;28:97-103.

39. Bae KH, Kim C, Paik DI, Kim JB. A comparison of oral health related quality of life between complete and partial removable denture-wearing older adults in Korea. J Oral Rehabil. 2006;33:317-22.

40. Ayala-Luis J, Johansson V, Sampogna F, Axtelius B, Söderfeldt B. A multivariable analysis of patient dental satisfaction and oral health-related quality-of-life. A cross-sectional study based on DVSS and OHIP-14. Acta Odontol Scand. 2014;72(3):187-93.

41. Wong MCM, Liu JKS, Lo ECM. Translation and validation of the Chinese version of GOHAl. J Public Health Dent. 2002;62(2):78-83.

doi:10.1186/1472-6831-15-1

Cite this article as: Yen et al.: Impact of removable dentures on oral health-related quality of life among elderly adults in Taiwan. BMC Oral Health 2015 15:1.

\section{Submit your next manuscript to BioMed Central and take full advantage of:}

- Convenient online submission

- Thorough peer review

- No space constraints or color figure charges

- Immediate publication on acceptance

- Inclusion in PubMed, CAS, Scopus and Google Scholar

- Research which is freely available for redistribution 